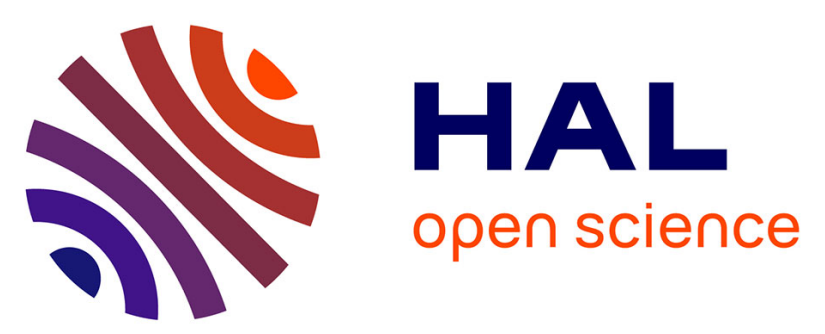

\title{
Doppler-Based Ground Speed Sensor Fusion and Slip Control for a Wheeled Rover
}

Damien Lhomme-Desages, Christophe Grand, Faïz Ben Amar, Jean-Claude Guinot

\section{- To cite this version:}

Damien Lhomme-Desages, Christophe Grand, Faïz Ben Amar, Jean-Claude Guinot. Doppler-Based Ground Speed Sensor Fusion and Slip Control for a Wheeled Rover. IEEE/ASME Transactions on Mechatronics, 2009, 14 (4), pp.484-492. 10.1109/TMECH.2009.2013713 . hal-00733597

\section{HAL Id: hal-00733597 https://hal.science/hal-00733597}

Submitted on 19 Sep 2012

HAL is a multi-disciplinary open access archive for the deposit and dissemination of scientific research documents, whether they are published or not. The documents may come from teaching and research institutions in France or abroad, or from public or private research centers.
L'archive ouverte pluridisciplinaire HAL, est destinée au dépôt et à la diffusion de documents scientifiques de niveau recherche, publiés ou non, émanant des établissements d'enseignement et de recherche français ou étrangers, des laboratoires publics ou privés. 


\title{
Doppler-based Ground Speed Sensor Fusion and Slip Control for a Wheeled Rover
}

\author{
Damien Lhomme-Desages, Christophe Grand, Faïz Ben Amar and Jean-Claude Guinot, Member, IEEE
}

\begin{abstract}
High speed unmanned ground vehicles evolving on natural terrains can exhibit a significant slip and skid. An estimation of both friction and traction forces can allow to achieve a better control. In order to implement a control architecture based on the vehicle dynamic model and the wheel-soil interaction model, the knowledge of the wheels slip rate is required. The wheel angular velocities can be precisely measured. But the true measurement of the ground speed of the vehicle is much more challenging. A low-cost Doppler radar is used, in conjunction with an accelerometer, to obtain the ground speed. Thus, the knowledge of the slip rate allows us to set up an in-situ procedure for the estimation of soil parameters that is based on the measurement of the motors torques. A wheel slippage controler has also been implemented, which is a first step toward high-level dynamic control.
\end{abstract}

Index Terms-field robotics, slippage, rover, wheel-soil interaction, Doppler.

\section{INTRODUCTION}

I $\mathrm{N}$ recent years, much interest has been focused on high speed off-road autonomous wheeled vehicles. This field raises specific issues such as the way to take into account dynamic effects in obstacle avoidance or in path tracking. The concept of high velocity for ground vehicles depends on the vehicle itself and the environment traveled over. As an example, recent planetary rovers have an average velocity of about $1 \mathrm{~km}$ per day [1], which may be insufficient for large scale exploration.

In the design of controllers for wheeled mobile robots, it is usually assumed that wheels are rolling without slipping. This leads to introduce a non-holonomic constraint in the kinematic or dynamic model (see [2] for an example). This assumption is quite legitimate for usual applications such as autonomous vehicles on asphalted roads or slow robots used for indoor exploration. However, it is no longer suitable for many applications where wheel slip cannot be neglected [3], especially for traveling at high speed over natural soils [4].

Due to the dynamics of the vehicle and the saturation of admissible forces by the soil, the wheels are slipping when the rover is moving on such terrains. Thus, the stability of the path tracking control cannot be guaranteed with the classical control architectures. Therefore, the distance to the desired path can be large and hard to quantify, which could be a problem to achieve a correct corridor tracking or obstacle avoidance.

In a previous work [5], we proposed a model-based controler applied to a skid-steering autonomous mobile robot

Manuscript received June, 2008; revised November, 2008

UPMC Univ Paris 06, ISIR, F-75005, Paris, France

e-mail: christophe.grand@upmc.fr

Regular paper, Technical area: Robotics evolving at high velocity on soft soils such as sand, where slip and skid phenomena can be significant. Slippage was taken into account, not as a perturbation, but as a genuine input that we intended to use in order to master traction forces.

In this work, the terrains considered are horizontal and relatively smooth compared to the size of the wheels, but with a low cohesion. The point here is the practical implementation of the slippage measurement, which is basically a ratio between, on the one hand, the speed of the center of the wheel with respect to the ground, and on the other hand, the velocity of the wheel at the soil contact point with respect to the hub.

The definition we use for the slip is given in section II, where we also develop the model we adopt for the computation of the traction force [6]. A lightweight skid-steering rover has been developped to demonstrate the feasability of these concepts. In section III, the description of this experimental platform can be found. As the rotational speed of each wheel is relatively easy to measure, we focus on the estimation of the true speed of the vehicle, since we cannot rely on contact methods. Section IV describes our experimental device that has been mounted and tested onto the rover. Then in section $\mathrm{V}$, an in situ soil identification procedure which is based on the slippage estimation and the wheel-soil interaction model, is proposed so that the path controller is able to adapt to a specific soil. In the section VI, we present some experimental results on the control issues. The estimated ground speed is used to control the velocity of the robot, independently from the wheels velocity and from the conditions of slippage. Then, we present experiments on control of wheel slip.

\section{WHEEL-SOIL INTERACTION MODEL}

Several modeling frameworks can be used to compute the forces involved in the wheel-soil interaction process (As an example, a sophisticated empirical road-tyre model can be found in [7]). We selected a wheel-soil interaction model adapted to non-cohesive soils. This model is semi-empirical: it is based on data fitting of experimental data and shows that the raw traction force depends on the slip rate.

\section{A. Slip rate}

We consider only the longitudinal motion. Let $v$ be the linear velocity of the center of the wheel, $\omega$ the angular velocity of the wheel and $R$ the wheel radius. $v$ and $\omega$ are algebraic values relative to the frame attached to the hub.

In the model, the traction force depends on the slip rate $s$, which is defined as: 


$$
s=\left\{\begin{array}{lll}
1-\frac{v}{\omega R} & \text { if } & R \omega \geq v \\
\frac{\omega R}{v}-1 & \text { if } & R \omega<v \\
0 & \text { if } & \omega=v=0
\end{array}\right.
$$

for $v \geq 0$ and $\omega \geq 0$. Thus, $s>0$ for traction and $s<0$ for braking. We have also $1>s>-1$. Note that $s=0$ means rolling without slipping.

\section{B. Terramechanics model}

We use an extended version of the terramechanics model introduced by Bekker [8][6]. We assume that the entire wheel is relatively stiff compared to the ground so that we can consider the wheel rigid (Fig. 1).
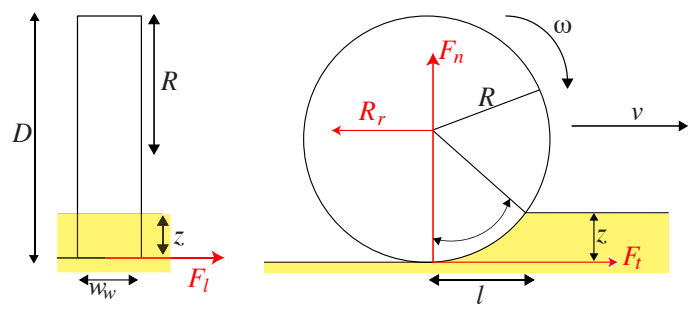

Fig. 1. Model of a rigid wheel

For each wheel, the net longitudinal force $D P$ (drawbar pull) is the difference between the raw traction force $F_{t}$ and the rolling resistance $R_{r}$ :

$$
D P(s)=F_{t}(s)-R_{r}
$$

The rolling resistance is the sum of several contributions:

$$
R_{r}=R_{c}+R_{h}+R_{b}
$$

where $R_{c}$ is the resistance due to the compaction of the soil, $R_{b}$ is the bulldozing resistance, resulting from the material displacement. $R_{h}$ stems from hysteresis effects of tyre distortion.

For horizontal terrains, we can assume that the rolling resistance is mainly caused by soil compaction, and is a function of the penetration depth $z$ :

$$
R_{r}=w_{w} \frac{z^{n+1}}{n+1}\left(\frac{k_{c}}{r}+k_{\phi}\right)
$$

where $k_{c}, k_{\phi}$ and $n$ are Bekker's soil parameters. $w_{w}$ is the width of the wheel. $r=\min \left(w_{w}, l\right), l$ being the length of the contact patch. The tractive force is related to the slip rate $s$ :

$$
F_{t}(s)=F_{m}\left[1-\frac{K}{s . l}\left(1-e^{-s . l / K}\right)\right]
$$

where $F_{m}=l w_{w} c+F_{n} \tan \phi . c, \phi$ and $K$ are soil parameters. $F_{n}$ is the normal force applied on one wheel. $F_{t}(s)$ is a monotonic function and it reaches its extreme values $\pm F_{t, \max }$ for extreme values of $s$.

This contact model has been validated by experimental measurements on an instrumented test bench (Fig. 2).

An actuated carriage moves the wheel with a given velocity. The wheel itself is rotated at a given speed. So the slip rate is imposed as the wheel traverses the terrain. A force sensor

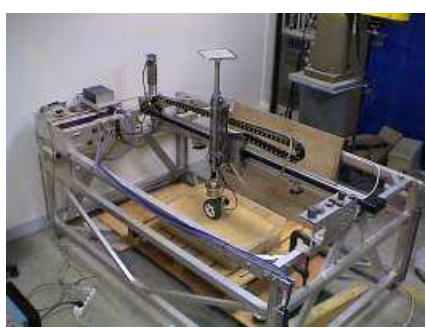

(a) Experimental bench

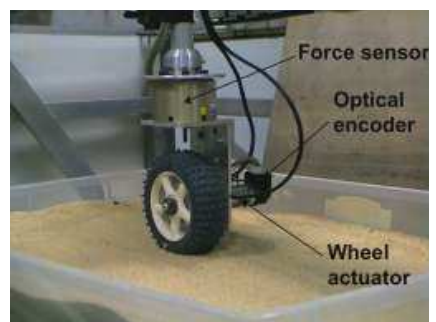

(b) Close-up
Fig. 2. Experimental device

is mounted above the wheel, to measure the forces generated by the wheel on the supporting structure, including the net traction force. Different types of wheels can be tested. A normal force can also be set by adding reference weights on a tray.

A set of experimental data is depicted in Fig. 3 [9].

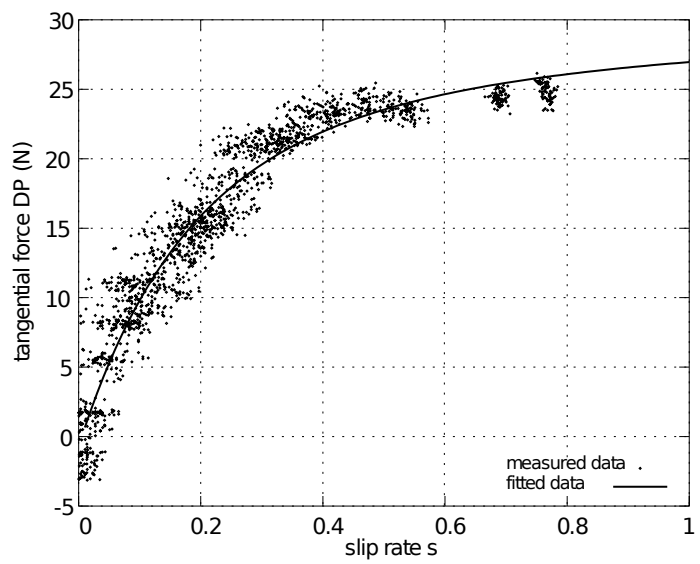

Fig. 3. Experimental measure of drawbar pull

A curve-fitting algorithm is used to find the soil parameters of the interaction model. The resulting curve fits quite precisely to the data, despite a high experimental noise of about $\pm 5 \mathrm{~N}$ on force measurement.

\section{ROVER DESCRIPTION}

All experiments are made with a skid-steering vehicle with four independent electrically driven wheels (Fig. 4 and 5). This is an autonomous low-cost platform, driven by a $400 \mathrm{MHz}$ onboard PC (K-Team Korebot). The kinematic and geometric parameters of the vehicle are detailed in table I.

A passive revolute joint has been introduced between both sides of the platform to ensure four permanent contacts with the ground. The center of mass $G$ is approximately located at the center of the platform.

This rover is equipped with four optical encoders with a resolution of 120 pulses per revolution (PPR) (gear ratio is 50:1). An accelerometer is used to measure the longitudinal acceleration. Low level control of motors is done by four microcontrollers that can measure current flowing through MOSFET drivers. The speed of wheels is servoed with proportional-integral-derivative controllers (PID) and gains 


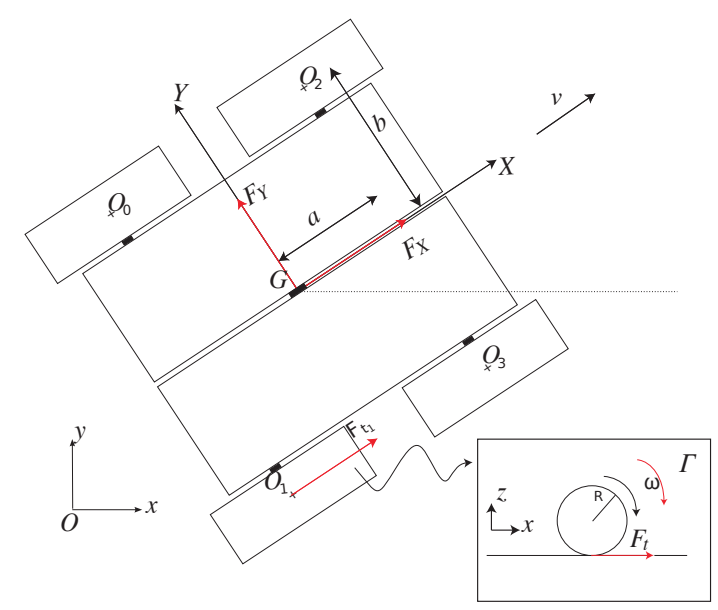

Fig. 4. Model of the four-wheel rover

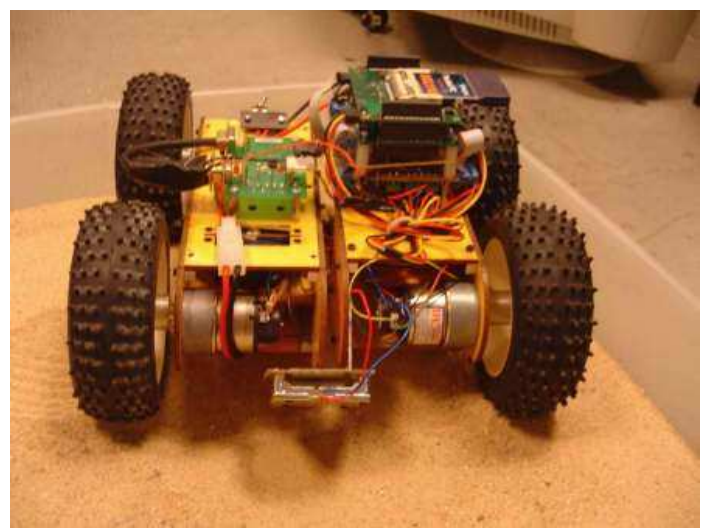

Fig. 5. Skid-steering demonstrator

have been empirically set. High level control is done by an onboard microprocessor.

Each wheel is made of a plastic rim and a rubber tyre containing a piece of high density polymer foam. An aluminium hub ensures the transmission of power from the motor shaft. Motors have a maximum mechanical power of $4 \mathrm{~W}$.

Remote supervision and data reception are done through a Wifi interface.

\section{GROUND SPEED MEASUREMENT}

In order to measure the slip rate, a measurement or estimation of the true velocity of the vehicle with respect to the ground is necessary, without resorting to wheel-based methods (optical encoders, resolvers).

Several techniques exist for this purpose and we can classify them into three main categories:

- Acceleration integration

- Position differentiation

- Direct speed measurement

The first one is a dead-reckoning method which involves an inertial sensor. The accelerometric data is time-integrated. However, this kind of method is subject to drift and is practically unusable, especially for low-cost sensors. Actually inertial sensor data is often fused with drift-less measurements.
TABLE I

ROVER PARAMETERS

\begin{tabular}{|l|r|l|}
\hline$m_{r}$ & $150 \mathrm{~g}$ & wheel mass \\
$M$ & $2.88 \mathrm{~kg}$ & total mass \\
$J$ & $5 \mathrm{gm}^{2}$ & wheel inertia \\
$R$ & $5.7 \mathrm{~cm}$ & wheel radius (under load) \\
$w_{w}$ & $42 \mathrm{~mm}$ & wheel width \\
$L$ & $30 \mathrm{~cm}$ & total length \\
$W$ & $27 \mathrm{~cm}$ & total width \\
$H$ & $18.5 \mathrm{~cm}$ & total height \\
$a$ & $8.3 \mathrm{~cm}$ & half wheelbase \\
$b$ & $12 \mathrm{~cm}$ & half track width \\
$v_{\max }$ & $1 \mathrm{~m} / \mathrm{s}$ & maximum speed \\
\hline
\end{tabular}

Position differentiation consists of a wide variety of sensor and techniques, inboard or outboard, absolute or relative, with a large variety of range, accuracy and refresh rate. A popular position sensor is, for instance, global satellite positioning [10], [11], [12], which can be implemented onboard a small terrestrial rover but suffers important drawbacks. Because of the low refresh rate and the poor accuracy (for non-diffential GPS), fusion with other sensors is required (IMU, as in [13]). The signal quality may be poor, not to say inexistant, in urban environments. Furthermore, the sensor needs a satellite constellation that is not present for extra-terrestrial planetary missions. Thus, some authors propose to realize the fusion of only on-board sensors, including motor current, gyro and vision, in order to provide a more accurate estimation of wheel slippages [14]. Other authors have used visual odometry [15].

Among direct measurement methods, we can cite ultrasonic Doppler sensors [16] and electromagnetic Doppler sensors. A frequency analysis of GPS signal is possible and gives rather accurate data but the resfresh rate is still low (1Hz in general).

The solution we have chosen is based on a direct speed measurement from a low-cost Doppler radar (MDU1130). The base frequency is $9.9 \mathrm{GHz}$ (X-band). This kind of sensor has been used for many years in measuring the true speed for agricultural tractors on slippy soils [17][18].

Indeed there are more efficient ground speed sensors. Tab. II gives key information for some of them. The accuracy increases with the base frequency and the sharpness of the beam. But for light, cost efficient robotic applications, one should not need such heavy devices.

TABLE II

PARAMETERS OF SEVERAL RADARS

\begin{tabular}{|l|c|c|c|c|c|}
\hline model & frequency $(\mathrm{GHz})$ & beamwidth $\left({ }^{\circ}\right)$ & weight $(\mathrm{g})$ & cost & accuracy \\
\hline MDU1130 & 9.9 & $36 \times 72$ & 15 & - & - \\
DJ Radar II & 24.13 & $\approx 15$ & 2000 & + & + \\
DJ Radar III & 24.13 & $20 \times 16$ & 500 & + & + \\
DRS1000 & 35.5 & 12 & 230 & ++ & ++ \\
\hline
\end{tabular}

\section{A. Measurement principle}

The principle of the measure is the Doppler effect: an electromagnetic wave with a given frequency is received with a different frequency if the receiver is moving with respect to the transmitter.

Here, we use a radar pointed to the ground with a given angle and we measure a frequency shift proportional to the correspondant speed component (Fig. 6). 


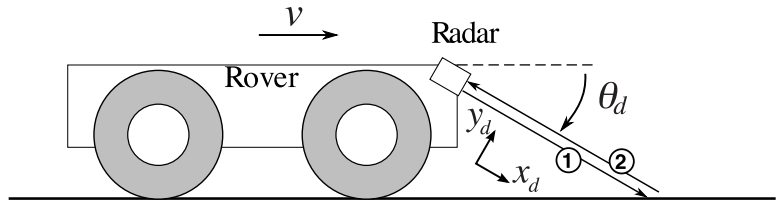

Fig. 6. Attachment of the sensor

The general formula for the non-relativist Doppler effect is:

$$
f_{a}=\frac{c-v_{r}}{c-v_{s}} f_{0}
$$

where: $f_{0}$ is the base frequency of the emitted wave, $v_{r}$ the speed of the receiver and $v_{s}$ the speed of the source. Here, $c$ is the propagation velocity of electromagnetic waves. This gives the apparent frequency $f_{a}$.

Therefore, the apparent frequency of the wave received by the ground is:

$$
f_{1}=\frac{1}{1-\frac{v_{d}}{c}} f_{0}
$$

where $v_{d}$ is the component of the velocity along $x_{d}$.

The reflected wave has the same frequency $f_{1}$. The apparent frequency of the wave received by the vehicle (reflected wave) is then:

$$
f_{2}=\left(1+\frac{v_{d}}{c}\right) f_{1}
$$

hence:

$$
f_{2}=\frac{c+v_{d}}{c-v_{d}} f_{0}
$$

A first order limited development gives (we have $v_{d}<<c$ ):

$$
f_{2}=\left(1+2 \frac{v_{d}}{c}\right) f_{0}
$$

Therefore the frequency shift is:

$$
\Delta f=\frac{2 v_{d}}{c} f_{0}
$$

with $v_{d}=v \cos \theta_{d}$ where $\theta_{d}$ is the angle of the radar with respect to the horizontal plane.

Fig. 7 describes the frequency acquisition process. The mixer gives a signal composed of two frequency ( $\Delta f$ et $2 f_{0}+\Delta f$ ). The first filter eliminates the high frequency. The signal is then amplificated and filtered. The band-pass filter is set to cut frequencies below $3 \mathrm{~Hz}$ and above $80 \mathrm{~Hz}$. An analog-to-digital converter (ADC) gives data to a Fast Fourier transform routine (FFT) to obtain the power spectrum, in order to identify $\Delta f$. An offset voltage is added before the ADC to facilitate the acquisition of negative values, so the spectrum has a non zero value at zero frequency. $\Delta f$ is simply taken at the maximum of the power spectrum except zero frequency. The FFT is performed on a 256 samples window.

This process gives one data every $0.5 \mathrm{~s}$ approximately.

\section{B. Accuracy}

Due to the angular dispersion of the sensor, the frequency shift measurement is very noisy. On Fig. 8a is plotted the amplified signal for a speed of $0.18 \mathrm{~m} / \mathrm{s}$ on a concrete ground. Its spectrum is plotted on Fig. 8b.

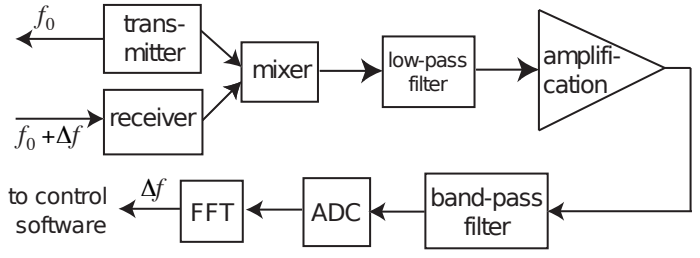

Fig. 7. Frequency acquisition process

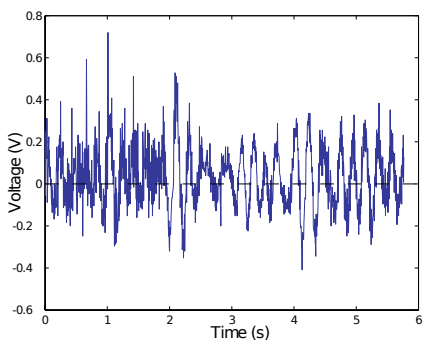

(a) Voltage vs Time

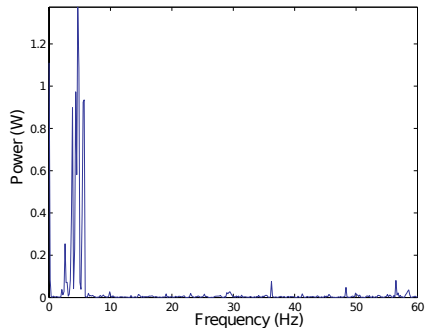

(b) Spectral power density
Fig. 8. Radar signal after amplification

According to [17], the relative error can be written as:

$$
v_{e}=\frac{1}{2 \cos \theta_{d}} \sqrt{\frac{c \alpha \sin \theta_{d}}{2 f_{0} v T_{p}}}
$$

where $\alpha$ is the beamwidth in the vertical plane (in rad) and $T_{p}$ the processing time.

In our case, for $\theta_{d}=20^{\circ}$ and $v=0.2 \mathrm{~m} / \mathrm{s}$, we have $v_{e}=10 \%$, which can be acceptable for this sensor. The accuracy will be better with higher frequencies $(24 \mathrm{GHz}$ or even $35 \mathrm{GHz}$ ). The processing time cannot be too much increased, as it would introduce delay into the control loop. The error is also dependent on the angle of incidence $\theta_{d}$. Authors generally choose an angle of $35-40^{\circ}$. We found that $20^{\circ}$ was a good compromise between accuracy, power received and mechanical constraints.

The most problematic parameter in our case is the beamwidth of the radar, which is relatively high, and leads to highly noisy measures. However, some promising results could be obtained.

\section{Sensor Fusion}

We use a simple Kalman filter to fuse doppler data and accelerometer data, in order to estimate the longitudinal velocity.

The filter gives an estimate $\hat{v}$ of the ground speed from the radar measure $v_{\text {doppler }}$ and the acceleration $a_{x}$. The process noise $\xi$ is the noise of the accelerometer. Its variance is taken from its specifications. $\eta$ is the noise on the Doppler measure, which is considered gaussian. Its variance has been measured. The state vector is simply $x=(v)$. Process equations are simple:

$$
\begin{aligned}
v(k+1) & =v(k)+\left(a_{x}(k)+\xi(k)\right) \Delta T \\
v_{\text {doppler }}(k) & =v(k)+\eta(k)
\end{aligned}
$$

The sample time $\Delta T$ of the filter is $10 \mathrm{~ms}$. 


\section{Sensor Validation}

An external sensor has been used in order to validate our sensor. It consists in a set of video cameras following a target attached to the robot (Scheme in Fig. 9(a)). Thus, a precise recording of its trajectory can be achieved (accuracy of $1 \mathrm{~mm}$ at $7 \mathrm{~Hz}$ ). The speed is obtained by time differentiation of the positions. The picture in Fig. 9(b) is one of the frames of the recording sequence.

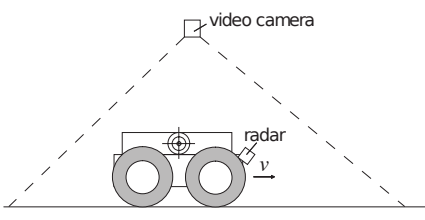

(a) Concept of sensor validation

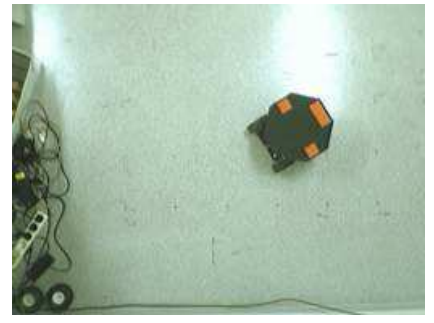

(b) Robot localization
Fig. 9. Vision system for sensor validation

Then, we compare the velocity given by our sensor fusion and the one computed by this vision system (Fig. 10). It was found that the absolute value given by the radar is correct but with a high measurement noise. The accuracy is better for higher speeds $( \pm 10 \%$ at $1 \mathrm{~m} / \mathrm{s})$.

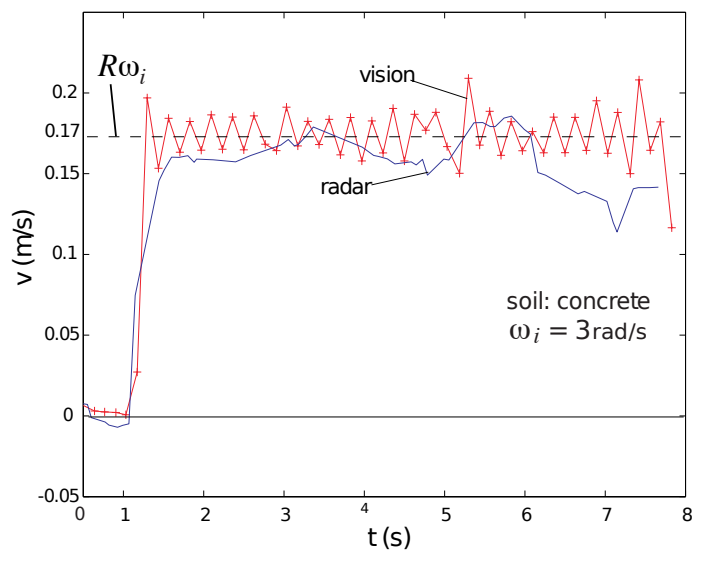

Fig. 10. Comparison of speed measurements between vision system and radar-based sensor

\section{IN-SITU SLIP-FORCE SOIL CHARACTERISTICS MEASUREMENT}

In order to build a model-based control law, soil parameters are needed to compute interaction forces. Therefore, an estimation algorithm is required. This problem is not trivial and can requires complex sensing systems. For example, in [19], author proposed a prototype of a wheel tread deformation sensing system that can be used to capture the wheel/ground friction characteristics.

Here, we limit ourselves to an offline estimation of soil parameters, assuming that the ground surface is homogeneous and that these parameters have a negligible variation during the displacement. On the basis of this strong assumption an estimation procedure can be set up. This procedure has to be run before the trajectory or path control phase.

The concept is to measure motor currents while forcing the slip rate to vary between two specified bounds. We impose a given slip on front wheels by controlling their rotational speed and by regulating the speed of the platform (using method presented in section VI).

This method is similar to the one described in [20] (method III), except that the ground speed is measured and that we take into account the dynamic model of the wheels.

The desired front wheels angular velocity are

$$
\omega_{2,3}=\dot{\omega}_{a} t
$$

where $\dot{\omega}_{a}$ is a constant.

A constant platform speed is obtained by controlling rear wheels speed with the following control law:

$$
\omega_{0,1}=\frac{v^{*}}{R}+K_{v}\left(v^{*}-v\right)
$$

The desired value of ground speed is $0.3 \mathrm{~m} / \mathrm{s}$. Fig. 11(b) and 11(a) show the evolution of wheel velocities.

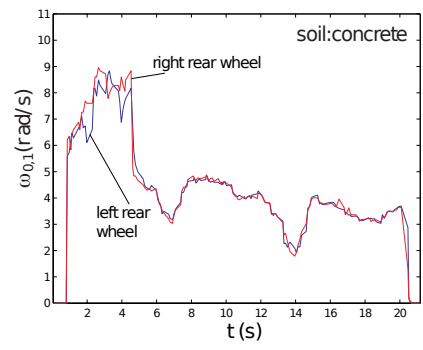

(a) Rear wheels

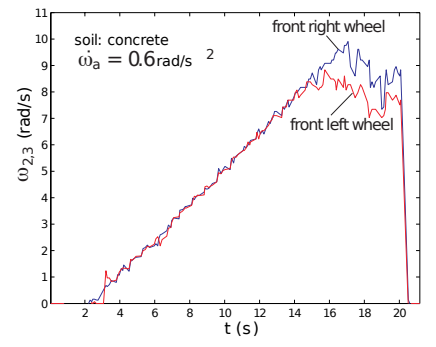

(b) Front wheels
Fig. 11. Angular velocity of wheels during soil estimation

The lack of accuracy in the tracking is mainly due to large inaccuracy on the speed estimate. Note also the high characteristic time (about 2 seconds) because of the high convergence time of the Kalman filter.

Fig. 12 shows a typical result. Front wheel slip is slowly increasing from -1 (wheels are blocked) to 0.4 (actually actuators saturate at this value), while rear wheel slip is decreasing symmetrically to maintain the overall speed constant. At $t=10 \mathrm{~s}$, all wheels have the same velocity and roll without slipping. This estimation phase lasts about $20 \mathrm{~s}$. We isolate the growing part of this curve for one testing wheel (dash box).

Meanwhile, front wheel motor currents $I_{2}$ and $I_{3}$ are measured. Thus, we can plot the slip-current curve (Fig. 13).

From data, an experimental relation between slip and traction force can be depicted. This curve characterizes the longitudinal interaction. It can be fitted by the terramechanics model, in order to find soil parameters.

Furthermore, the wheel dynamics can be written:

$$
\Gamma_{i}=K_{\Gamma} I_{i}=\Gamma_{r i}+J \dot{\omega}_{i}+R F_{t i} \quad i=2,3
$$

where $F_{t i}$ is the raw traction force and $I_{i}$ the current consumed by motor $i . K_{\Gamma}$ is the torque constant of the gear motor taken from specifications $\left(K_{\Gamma}=0.265 \mathrm{Nm} / A\right) . \Gamma_{r i}$ is the resistant torque for wheel $i$. It has been identified by measuring the 


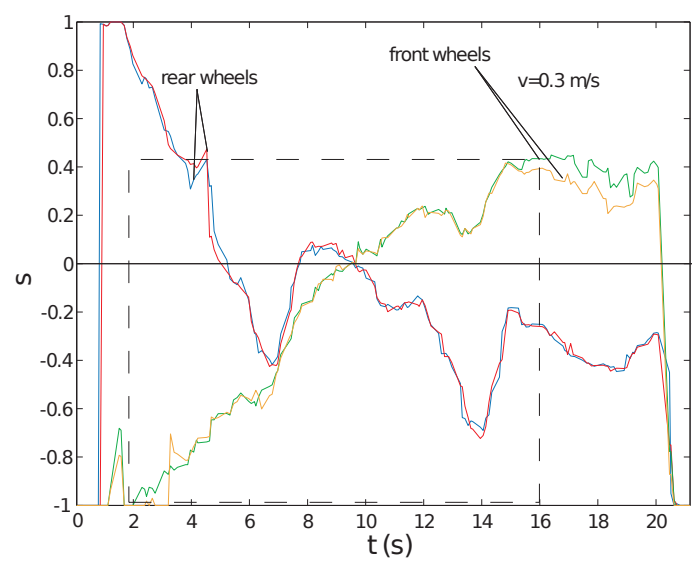

Fig. 12. Slip rates for each wheel during the identification process

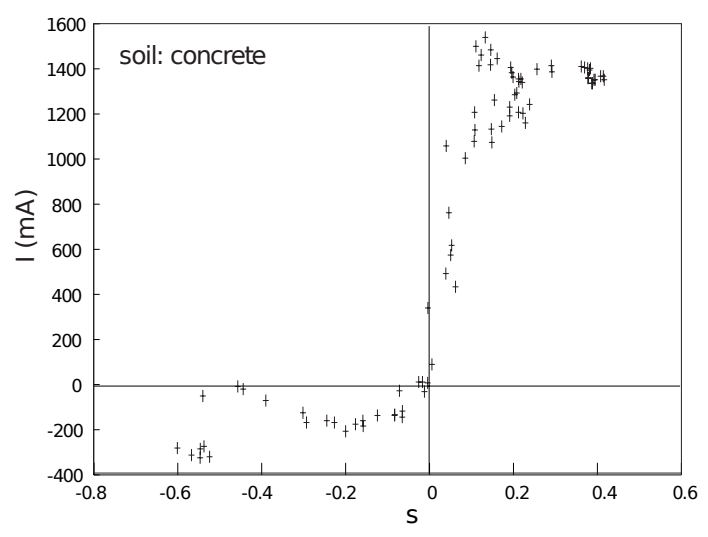

Fig. 13. Slip-current relation

current and the angular velocity for each wheel under no-load condition:

$$
\Gamma_{r i}=1.6 .10^{-3} \omega_{i}+0,03 N m \quad i=2,3
$$

with $\omega_{i}$ in rad/s. The angular acceleration $\dot{\omega}_{0}$ is a constant parameter of the experiment.

The inertia $J$ of the wheel-motor system can be identified offline by applying a constant acceleration under no-load condition $\left(J=5 \cdot 10^{-3} \mathrm{kgm}^{2}\right)$.

From (17), we have:

$$
F_{t i}=\frac{1}{R}\left(K_{\Gamma} I_{i}-\Gamma_{r i}\left(\omega_{i}\right)-J \dot{\omega}_{i}\right) \quad i=2,3
$$

Finally, the slip-raw traction force relation can be found using (19) (Fig. 14).

For sand and gravel, the data are fitted with the terramechanics model (equation (5)). Actually, the accuracy of measurements does not permit to estimate the rolling resistance, so we neglect it. The length $l$ of the contact patch is unknown since we cannot measure the sinkage $z$. It is not possible to separate the contributions of cohesion and friction so we have two aggregated parameters to estimate: $F_{m}$ and $s_{c}=\frac{K}{l}$ :

$$
F_{t}(s)=F_{m}\left[1-\frac{s_{c}}{s}\left(1-e^{-\frac{s}{s_{c}}}\right)\right]
$$

For concrete, the data is fitted with the model:

$$
F_{t}(s)=F_{m}\left(1-e^{-\frac{s}{s_{c}}}\right)
$$

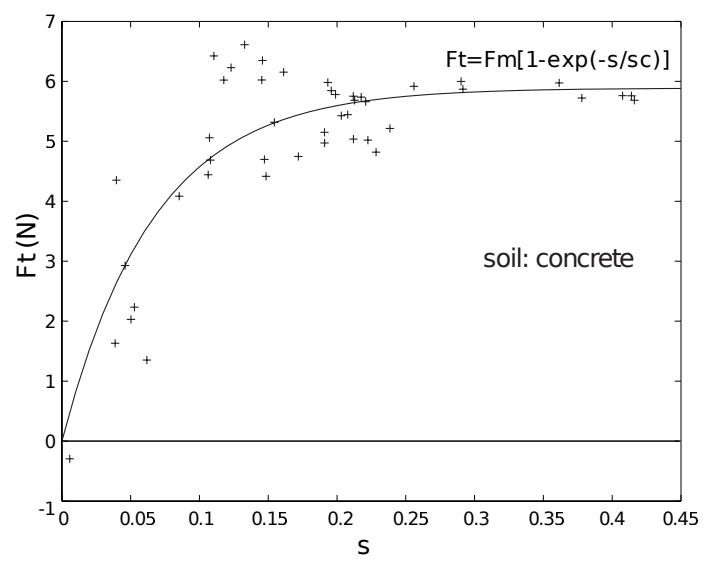

Fig. 14. Slip-traction force relation for concrete

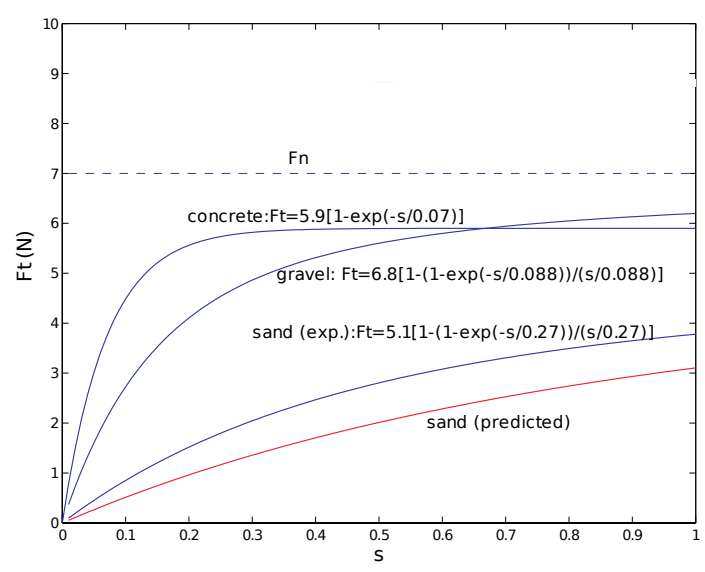

Fig. 15. Data interpolation for several soils

with $F_{m}=\mu F_{n}$. This is a simplified version of the empirical Burckhardt model [21], commonly used for tyre-road interaction. $\mu$ is the static friction coefficient. The parameters of this model are $\mu$ and $s_{c}$. The normal force $F_{n}$ is assumed to be one quarter of the total weight. This gives $F_{n}=7 N$. We found $\mu=0.8$ (as a rough guide, [22] gives $\mu=0.5-0.9$ for rubber on concrete).

Our final result of this analysis is a comparison between data fittings for various soils (Fig. 15). We have also plotted the vertical force $F_{n}$. The estimated parameters can be found in Tab. III.

TABLE III

Estimated Aggregated SoIl Parameters

\begin{tabular}{|l|c|c|}
\hline soil & $F_{m}(N)$ & $s_{c}$ \\
\hline sand & 5.1 & 0.27 \\
gravel & 6.8 & 0.088 \\
\hline
\end{tabular}

We notice that the maximum value for sand is lower than for gravel. It is probably due to the higher friction angle $\phi$ of gravel, because of a much more irregular shape of grains, and because the cohesion of gravel is very low.

A comparaison can be done with the predicted curve for sand computed from (5) with parameters taken from the litterature ([6], dry sand, Land Locomotion Lab) and $l=4 \mathrm{~cm}$. These parameters are $c=1040 \mathrm{~Pa}, \phi=28^{\circ}$ and $K=2 \mathrm{~cm}$. 


\section{Control issues}

The estimated ground speed allows to carry out longitudinal speed control of the rover. Combined with the encoders information, one is able to control also the slip rate.

\section{A. Speed control}

Platform speed control, independantly from slip conditions, can be applied with the following control law:

$$
\omega_{i}^{*}=\frac{v^{*}}{R}+K_{v}\left(v^{*}-v\right) \quad i \in[0,3]
$$

where $v^{*}$ is the desired platform velocity, and $K_{v}$ is a proportional gain.

Figure 16(a) and 16(b) illustrate an experiment highlighting speed control capabilities for concrete. Desired speed is $0.2 \mathrm{~m} / \mathrm{s}$. The system is disturbed by simulating actuators failures: some wheels are intentionnally blocked. The wheel 0 (left-rear) is blocked for $5<t<9 s$ and the wheel 1 (right-rear) is blocked for $t>10 \mathrm{~s}$.

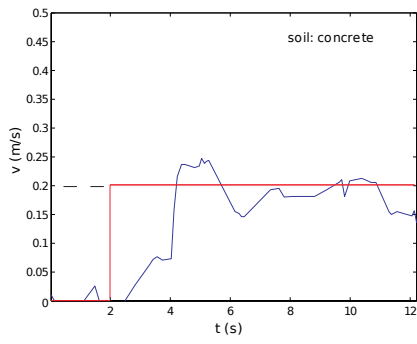

(a) Platform speed

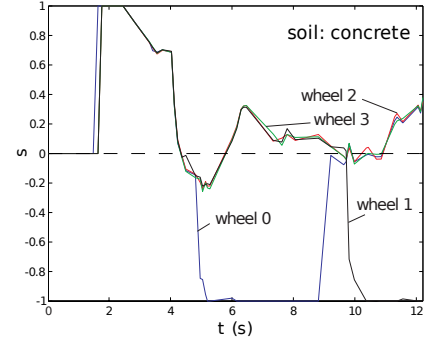

(b) Slip rates
Fig. 16. Experiment of speed control

Since only the longitudinal velocity is controlled, the heading of the vehicule changes during the motion as we block the wheels asymmetrically with respect to the sagittal plane. This result shows that the robot can roughly regulate its velocity even in presence of strong slip conditions.

\section{B. Slip servoing}

Several slip control methods exist in the literature, including nonlinear and gain-scheduled PID, sliding mode [23], fuzzy logic [24], or Lyapunov synthesis [25]. Recently, simple slip controllers have been used for mobile robots in rough terrain [26][27]. In the same way, we implement a PI-controller:

$$
U=K_{p s}\left(s^{*}-s\right)+K_{i s} \int\left(s^{*}-s\right) d t
$$

where $U$ is the PWM rate of motor input. $s^{*}$ is the desired slip rate. The gains $K_{p s}$ and $K_{i s}$ have been found empirically. And for each wheel, the actual slip rate is estimated.

Fig. 17(a) shows an example of wheel slip control on concrete ground. The desired value is $40 \%$. Other wheels are submitted to the control law (22) and do not slip or slip lightly. For natural non cohesive soils, such as gravel (Fig. 17(b)) and sand (Fig. 17(c)), the tracking is much more coarse, due to vibrations and heterogeneity of the surface.

These are encouraging results, in view of the quality of sensors, that show that one can design innovative control based on a better knowledge of the interaction with ground.
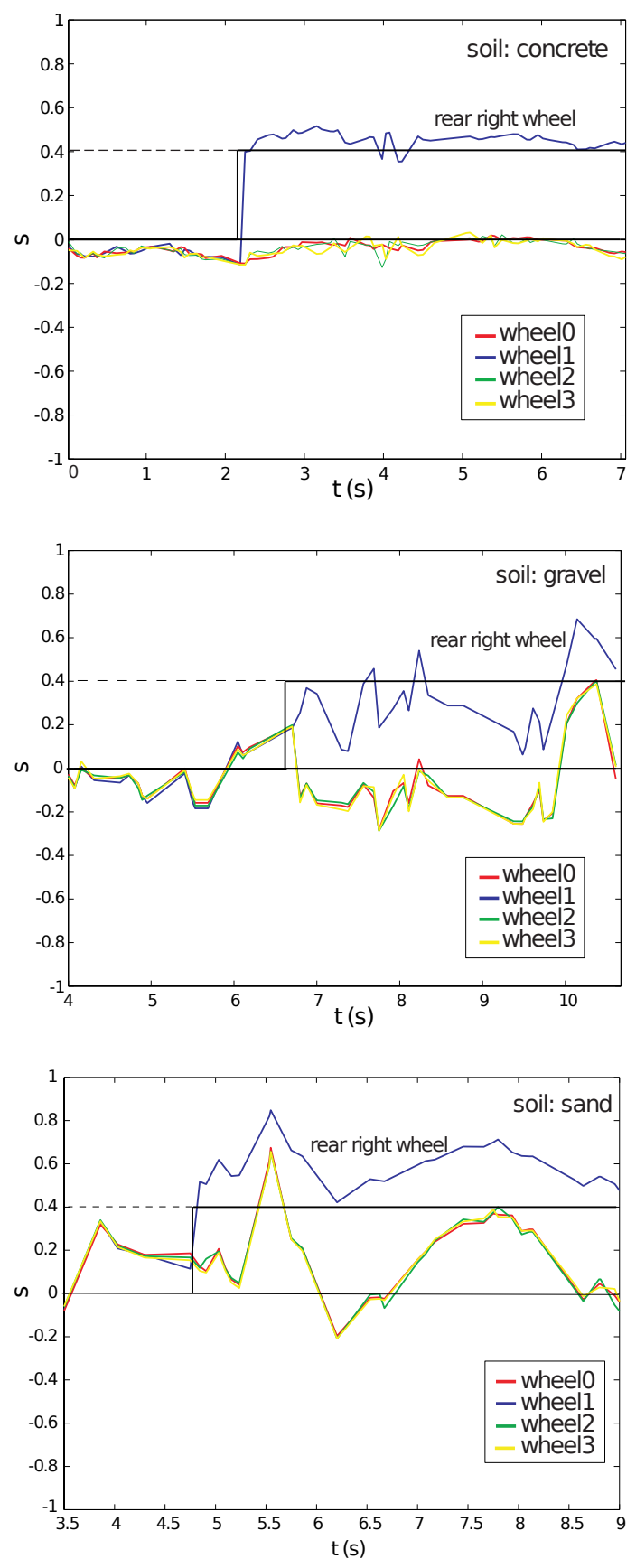

Fig. 17. Slip control for one wheel

\section{CONCLUSIONS AND FUTURE WORKS}

A low-cost radar sensor has been set up to measure the ground speed of a small wheeled mobile robot. A Kalman fusion algorithm was used to combine this information with inertial data and improve the measurement. It was consequently possible to measure the slip rate for each wheel.

A simple procedure for the in-situ estimation of the wheelsoil interaction parameters has been designed. This procedure which has been implemented and tested off-line, allows the system to get the slip-torque relation in the contact area, and eventually gives the slip-traction force relation of the interaction.

The control of the slip rate is a further step that makes it 
possible to control traction forces. In the future, a model-based control architecture will be implemented and the path tracking control at high speed will be experimentally studied.

\section{REFERENCES}

[1] J. Biesiadecki, E. Baumgartner, R. Bonitz, B. Cooper, F. Hartman, P. Leger, M. Maimone, S. Maxwell, A. Trebi-Ollennu, E. Tunstel, and J. Wright, "Mars exploration rover surface operations: driving opportunity at meridiani planum," IEEE Robot. Autom. Mag., vol. 13, no. 2, pp. 63-71, Jun. 2006.

[2] L. Caracciolo, A. De Luca, and S. Iannitti, "Trajectory tracking control of a four-wheel differentially driven mobile robot," in Proc. IEEE Int. Conf. Robot. Autom., Detroit, MI, USA, May 1999, pp. 2632-2638.

[3] T. Huntsberger, H. Aghazarian, Y. Cheng, E. Baumgartner, E. Tunstel, C. Leger, A. Trebi-Ollennu, and P. S. Schenker, "Rover autonomy for long range navigation and science data acquisition on planetary surfaces," in Proc. IEEE Int. Conf. Robot. Autom., Washington DC, USA, May 2002, pp. 3161-3168.

[4] M. Spenko, K. Iagnemma, and S. Dubowsky, "High speed hazard avoidance for mobile robots in rough terrain," in SPIE Conf. on Unmanned Ground Vehicles, Orlando, FL, USA, Apr. 2004.

[5] D. Lhomme-Desages, C. Grand, and J.-C. Guinot, "Trajectory control of a four-wheel skid-steering vehicle over soft terrain using a physical interaction model," in Proc. IEEE Int. Conf. Robot. Autom., Rome, Italy, Apr. 2007, pp. 1164-1169.

[6] J. Y. Wong, Terramechanics and Off-Road Vehicles. Elsevier, 1989.

[7] H. Pacejka, Tyre and Vehicle Dynamics. Elsevier, 2002.

[8] M. Bekker, Introduction to Terrains-Vehicles Systems. The University of Michigan Press, 1969.

[9] C. Grand, "Optimisation et commande des modes de déplacement des systèmes locomoteurs hybrides roue-patte. application au robot Hylos (in french)," Ph.D. dissertation, Pierre et Marie Curie University, Paris, France, 2004.

[10] R. Lenain, B. Thuilot, C. Cariou, and P. Martinet, "High accuracy path tracking for vehicles in presence of sliding: Application to farm vehicle automatic guidance for agricultural tasks," Auton. Robots, vol. 21, no. 1, pp. 79-97, 2006.

[11] S. Panzieri, F. Pascucci, and G. Ulivi, "An outdoor navigation system using gps and inertial platform," IEEE/ASME Transactions of Mechatronics, vol. 7, no. 2, pp. 134-142, Jun 2002.

[12] C. B. Low and D. Wang, "Gps-based tracking control for a carlike wheeled mobile robot with skidding and slipping," IEEE/ASME Transactions of Mechatronics, vol. 13, no. 4, pp. 480-484, Aug. 2008.

[13] C. Ward and K. Iagnemma, "Model-based wheel slip detection for outdoor mobile robots," in Proc. IEEE Int. Conf. Robot. Autom., Rome, Italy, Apr. 2007, pp. 2724-2729.

[14] G. Reina, L. Ojeda, A. Milella, and J. Borenstein, "Wheel slippage and sinkage detection for planetary rovers," IEEE/ASME Transactions of Mechatronics, vol. 11, no. 2, pp. 185-195, Apr. 2006.

[15] A. Angelova, L. Matthies, D. Helmick, and P. Perona, "Slip prediction using visual information," in Proc. Robotics: Science and Systems, Philadelphia, PA, USA, Aug. 2006.

[16] K. Imou, T. Okamoto, Y. Kaizu, and H. Yoshii, "Ultrasonic Doppler speed sensor for autonomous vehicles," J. of the Japanese Society of Agricultural Machinery, vol. 63, no. 2, pp. 39-46, 2001.

[17] W. Fleming and A. Hundiwal, "Radar ground speed sensors," in Proc. IEEE Veh. Tech. Conf., vol. 35, Farmington Hills, MI, USA, May 1985, pp. $262-272$.

[18] S. Stuchly, A. Thansandote, J. Mladek, and J. Townsend, "A Doppler radar velocity meter for agricultural tractors," IEEE Trans. Veh. Technol., vol. 27, no. 1, pp. 24-30, Feb. 1978.

[19] J. Yi, "A piezo-sensor-based 'smart tire' system for mobile robots and vehicles," IEEE/ASME Transactions of Mechatronics, vol. 13, no. 1, pp. 95-103, Feb. 2008.

[20] L. Ojeda, D. Cruz, G. Reina, and J. Borenstein, "Current-based slippage detection and odometry correction for mobile robots and planetary rovers," IEEE Trans. Robot., vol. 22, no. 2, pp. 366-378, Apr. 2006.

[21] U. Kiencke and L. Nielsen, Automotive Control Systems, For Engine, Driveline, and Vehicle. Springer Verlag, 2000.

[22] D. B. Marghitu and J. D. Irwin, Mechanical Engineer's Handbook. Elsevier, 2001.

[23] K. Buckholtz, "Reference input wheel slip tracking using sliding mode control," in SAE World Congress, Detroit, MI, USA, Mar. 2002.
[24] F. Yu, J.-Z. Feng, and J. Li, "A fuzzy logic controller design for vehicle ABS with a on-line optimized target wheel slip ratio," KSAE Int. J. of Automotive Technology, vol. 3, no. 4, pp. 165-170, 2002.

[25] J. Kalkkuhl, T. Johansen, and J. Ludemann, "Improved transient performance of nonlinear adaptive backstepping using estimator resetting based on multiple models," IEEE Trans. Autom. Control, vol. 47, pp. 136-140, 2002.

[26] K. Yoshida and H. Hamano, "Motion dynamics of a rover with slip-based traction model," in Proc. IEEE Int. Conf. Robot. Autom., Washington DC, USA, May 2002, pp. 3155-3160.

[27] D. Caltabiano, D. Ciancitto, and G. Muscato, "Experimental results on a traction control algorithm for mobile robots in volcano environment," in Proc. IEEE Int. Conf. Robot. Autom., New Orleans, LA, USA, Apr. 2004, pp. 4375-4380.

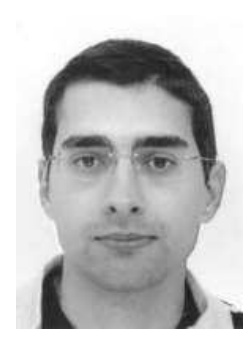

Damien Lhomme-Desages received M.Sc degree in Engineering from Ecole Centrale de Lyon (France) in 2003 and $\mathrm{Ph} . \mathrm{D}$. degree in mechanical engineering from Université Pierre et Marie Curie - UPMC (Paris, France), in 2008. He is currently postdoctoral researcher at CNES (french space agency).

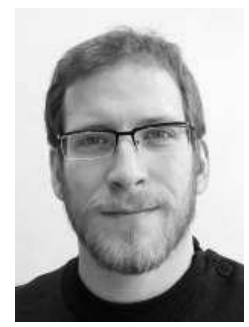

Christophe Grand was born in Paris, France in 1977. He is graduate from the Ecole Nationale Supérieure des Arts et Métiers (France). He received M.Sc and Ph.D. degrees in mechanical engineering from the Université Pierre et Marie Curie - UPMC (Paris, France) in 2000 and 2004, respectively.

$\mathrm{He}$ is associate professor since 2005 . His current research interests include mechatronics design, modeling, control and simulation of locomotion system, field robotics, vehicle-soil interaction modeling.

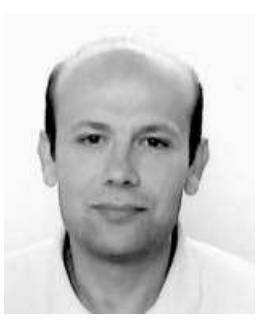

Faïz Ben Amar was born in Sfax, Tunisia in 1965 . $\mathrm{He}$ is graduate from the Ecole Nationale Supérieure des Arts et Métiers (France) and he received $\mathrm{PhD}$ degree in 1994 from the Université Pierre et Marie Curie - UPMC. He is associate professor since 1995.

Dr Faiz Ben Amar developed his researches in the field of design and control of high mobility locomotion systems and self-reconfigurable modular systems. He is interested in modelling and simulation of multibody systems interacting with complex environment.

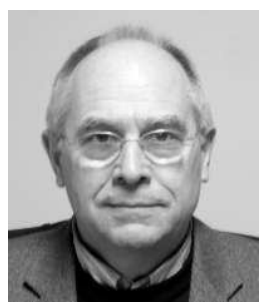

Jean-Claude Guinot was born in 1942. He received the diploma from the Ecole Nationale Supérieure des Arts et Métiers (1963), the diploma of doctorengineer (aerodynamics, 1967), the doctorat es sciences (acousto-optics, 1977). He is professor of Universities, from 1980, first at the LMS of the University of Poitiers, and, since 1983, at the UMPCParis Universitas. He was former directors of the LRP (Laboratoire de Robotique de Paris, UPMCCNRS) and the PhD Program of Mechanics, Acoustics, Electronics at the UPMC-Paris Universitas. 